\title{
Phosphonodifluoropyruvate is a mechanism-based
}

\section{inhibitor of phosphonopyruvate decarboxylase from}

\section{Bacteroides fragilis}

Katharina Pallitsch, ${ }^{1}$ Megan P. Rogers, ${ }^{2}$ Forest H. Andrews, ${ }^{2}$ Friedrich Hammerschmidt ${ }^{1} *$ and Michael J. McLeish ${ }^{2, *}$

${ }^{1}$ Institute of Organic Chemistry, University of Vienna, Vienna, Austria

${ }^{2}$ Department of Chemistry and Chemical Biology, Indiana University-Purdue University Indianapolis, Indianapolis, USA

*To whom correspondence should be addressed.

Email: $\underline{\text { mcleish@iupui.edu }}$

Address:

402 N. Blackford St.

Indianapolis IN 46202

USA

ABBREVIATIONS:

PnDFP, phosphonodifluoropyruvate; Phtase, phosphonatase from P. putida; PDC, pyruvate decarboxylase; PnPDC, phosphonopyruvate decarboxylase; ThDP, thiamin diphosphate; YADH, yeast alcohol dehydrogenase; DTT, dithiothreitol.

This is the author's manuscript of the article published in final edited form as:

Pallitsch, K., Rogers, M. P., Andrews, F. H., Hammerschmidt, F., \& McLeish, M. J. (2017).

Phosphonodifluoropyruvate is a mechanism-based inhibitor of phosphonopyruvate decarboxylase from Bacteroides fragilis. Bioorganic \& Medicinal Chemistry. https://doi.org/10.1016/j.bmc.2017.06.013 


\section{KEYWORDS}

Thiamin diphosphate; CD; UV-Vis, phosphonate, enzyme inhibition.

\section{ABSTRACT}

Bacteroides fragilis, a human pathogen, helps in the formation of intra-abdominal abscesses and is involved in $90 \%$ of anaerobic peritoneal infections. Phosphonopyruvate decarboxylase (PnPDC), a thiamin diphosphate (ThDP)-dependent enzyme, plays a key role in the formation of 2-aminoethylphosphonate, a component of the cell wall of B. fragilis. As such PnPDC is a possible target for therapeutic intervention in this, and other phosphonate producing organisms. However, the enzyme is of more general interest as it appears to be an evolutionary forerunner to the decarboxylase family of ThDP-dependent enzymes. To date, PnPDC has proved difficult to crystallize and no X-ray structures are available. In the past we have shown that ThDPdependent enzymes will often crystallize if the cofactor has been irreversibly inactivated. To explore this possibility, and the utility of inhibitors of phosphonate biosynthesis as potential antibiotics, we synthesized phosphonodifluoropyruvate (PnDFP) as a prospective mechanismbased inhibitor of PnPDC. Here we provide evidence that difluorophosphonopyruvate indeed inactivates the enzyme, that the inactivation is irreversible, and is accompanied by release of fluoride ion, i.e., PnDFP bears all the hallmarks of a mechanism-based inhibitor. Unfortunately, the enzyme remains refractive to crystallization. 


\section{Introduction}

Phosphonates, i.e., compounds having a C-P bond, are found in archaea, bacteria and eukaryotes and it has been suggested that they are important intermediates in the global phosphorus cycle. ${ }^{1,2}$ The relative stability of the $\mathrm{C}-\mathrm{P}$ bond makes phosphonolipids and phosphonoglycans less susceptible to enzymatic hydrolysis than phosphates, thereby providing a selective advantage in phosphate-limited environments. ${ }^{2}$ As phosphonates are structurally similar to phosphate esters and carboxylates, that same stability can also contribute to biological activity, with antibacterial, antiviral, antiparasitic and herbicidal activity all having been attributed to phosphonates. ${ }^{1,3}$

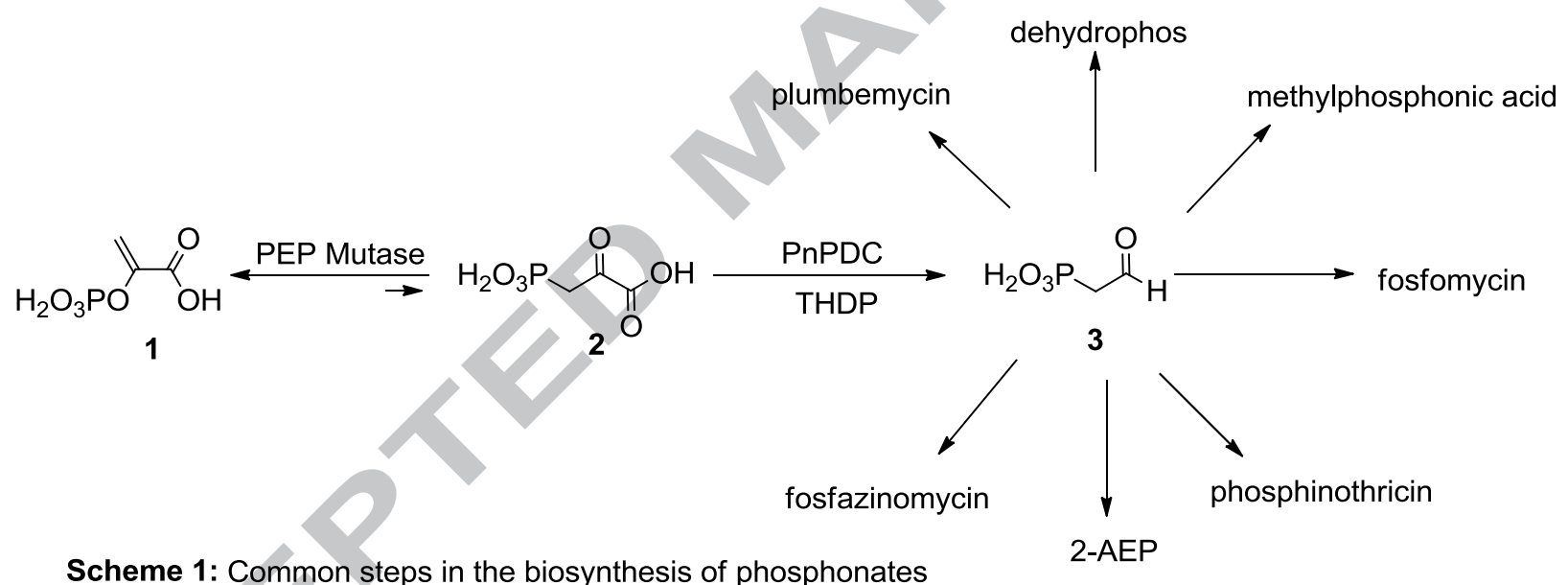

Scheme 1: Common steps in the biosynthesis of phosphonates

2-AEP

As shown in Scheme 1, there are two enzymes that are common to the biosynthesis of virtually all biogenic phosphonates. ${ }^{4,5}$ The first, PEP mutase, catalyzes the conversion of phosphoenolpyruvate $(\mathrm{PEP}, \mathbf{1})$ to phosphonopyruvate $(\mathrm{PnP}, 2)$. This reaction is thermodynamically unfavorable ${ }^{6}$ so a second enzyme, phosphonopyruvate decarboxylase (PnPDC), is used to introduce an irreversible step. ${ }^{7}$ Phosphonoacetaldehyde (PnAA, 3), the 
product of the decarboxylation reaction, is subsequently converted to a variety of phosphonic acid natural products.

Some of these products have found therapeutic use. Fosfomycin, a broad-spectrum antibiotic, is used in the treatment of cystitis. ${ }^{8}$ Plumbemycin ${ }^{5}$ and dehydrophos ${ }^{9}$ also act as antibiotics while phosphinothricin, as its tripeptide with two alanine residues (bialaphos), is a natural herbicide. ${ }^{10}$ 2-Aminoethylphosphonate (2-AEP) is used by microorganisms in a variety of ways. For many, it provides a source of useable carbon, nitrogen and phosphorus. ${ }^{11}$ For others, 2-AEP provides a counterpart to the lipid polar head group, phosphoethanolamine, that is resistant to chemical and enzymatic hydrolysis. ${ }^{12}$ Still others use it in the synthesis of bioactive compounds such as argolaphos, a broad-spectrum antibacterial phosphonopeptide. ${ }^{13}$ It is also notable that several well-known mammalian and plant pathogens produce phosphonates. Fosfomycin, for example, although it does have a therapeutic use, is produced by Pseudomonas syringae, a plant pathogen which infects fruit-bearing trees. ${ }^{14}$ Naegleria fowleri, known colloquially as the "brain-eating amoeba", causes meningoencephalitis in humans, and has been shown to produce phosphonates. ${ }^{15}$ In Bacteroides fragilis, a human pathogen involved in abscess formation, a 2AEP-containing capsular polysaccharide has been identified as the major virulence factor, ${ }^{12}$ while the genes for 2-AEP biosynthesis have been identified in Trypanosoma cruzi, the causative agent of Chagas' disease. ${ }^{16}$

Since phosphonate metabolism is not present in humans or higher plants/animals, it offers a promising target for drug design against these phosphonate producing and using pathogens. Intriguingly, the antibiotic action of dehydrophos provides a clue as to how this problem may be approached. Dehydrophos acts as a "Trojan horse" in that is taken into the cell by peptide permeases, whereupon it is activated by intracellular proteases to unmask methyl 
acetylphosphonate (MAP) ${ }^{4,17}$ a substrate analogue of pyruvate, ${ }^{18}$ and a potent mechanism-based inhibitor of both the E1 subunit of the pyruvate dehydrogenase complex ${ }^{19}$ and 1-deoxy-Dxylulose-5-phosphate (DXP) synthase. ${ }^{20}$ The inhibition is attributed to the reaction of these thiamin diphosphate (ThDP)-dependent enzymes with MAP producing a stable phosphonate analogue of the reaction intermediate, $\alpha$-lactylThDP. The analogue binds tightly and, in effect, irreversibly, to its targets. ${ }^{19} \beta$-Fluoropyruvate, another substrate analogue, also inactivates the pyruvate dehydrogenase complex by a ThDP-dependent mechanism. ${ }^{21,22}$ However, in this instance, addition of ThDP to fluoropyruvate is followed by decarboxylation, generating a carbanion and leading to elimination of fluoride. The resulting vinyl alcohol tautomerizes to give acetyl-ThDP which likely reacts with a nucleophile in the active site thereby inactivating the enzyme..$^{21,22}$

Given that phosphonopyruvate decarboxylase, which catalyzes the irreversible step in phosphonate biosynthesis, ${ }^{7}$ is also a ThDP-dependent decarboxylase, it would appear to be an ideal target for similar mechanism-based inhibitors. One such compound, shown in Scheme 2, is 3-phosphono-3,3-difluoropyruvate (PnDFP, 4) an analogue of the natural substrate,

phosphonopyruvate (3). It is expected that PnDFP will be accepted by the enzyme and react with the ThDP ylid to provide intermediate (5). However, following decarboxylation, the resulting carbanion (6) will eliminate fluoride to produce an inactive enol-ThDP complex (7). Potentially this could tautomerize to yield an phosphonofluoroacetyl-ThDP complex (8) but, regardless, the enzyme will remain inactivated. 
<smiles>[R][n+]1[c-]c(CCO[Po])c(C)[n+]([R])c1CCO[Po]</smiles>

4

ThDP ylid

5

$-\mathrm{CO}_{2}$<smiles>[R]N1C(C)=C(CCO[Po]=[Po])S/C1=C(\O)C(F)(F)C(F)(F)PO</smiles>

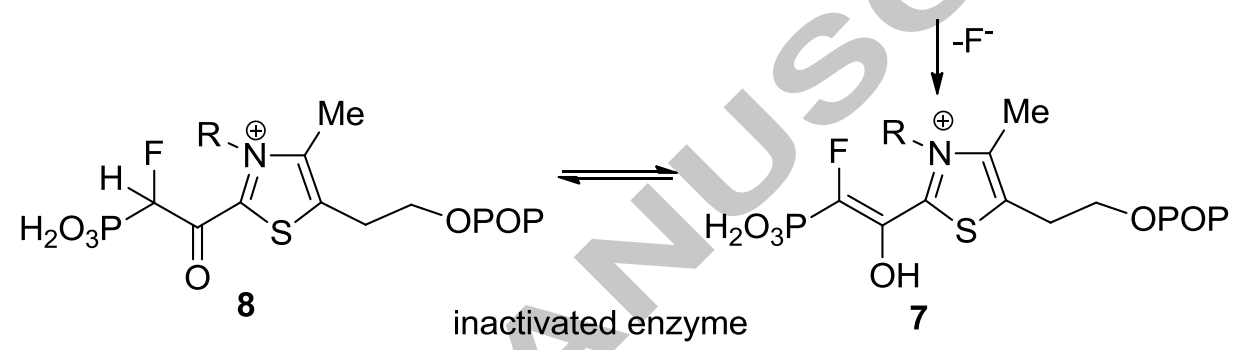

Scheme 2. Proposed mechanism of inactivation by PnDFP

In this paper we describe the synthesis and testing of $\mathbf{4}$ with the PnPDC from Bacteroides fragilis (BfPnPDC). PnDFP proved to be a potent inhibitor of the enzyme, and showed all the characteristics of a mechanism-based inhibitor. 


\section{Results}

\subsection{Synthesis of 3-phosphono-3,3-difluoropyruvate (PnDFP, 4)}

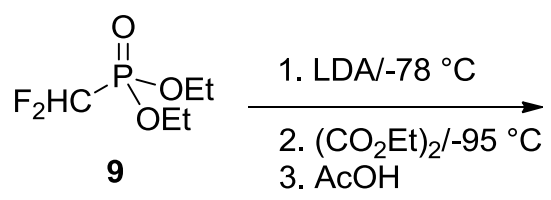

Scheme 3. Synthesis of PnDFP.<smiles>CCOC(=O)C(O)(O)[C-]P(=O)(OCC)OCC</smiles><smiles>CCOC(=O)C(=O)[Te-]P(=O)(OCC)OCC</smiles>

1. TMSBr/allylTMS $/ 60^{\circ} \mathrm{C}$

2. $\mathrm{NaOH} \mathrm{pH} 10$

3. Dowex $50 / \mathrm{H}^{+}$

4. $\mathrm{NaOH}$ to $\mathrm{pH} 7$

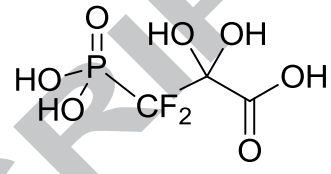

4 as its sodium salt

PnDFP (4) could be obtained in three steps from diethyl difluoromethylphosphonate (9) by deprotonation with freshly prepared lithium diisopropylamide (LDA) at $-78{ }^{\circ} \mathrm{C}$ (Scheme 3$)$. The resulting difluoromethyllithium could be reacted with diethyl oxalate $\left(\left(\mathrm{CO}_{2} \mathrm{Et}\right)_{2}\right)$, followed by acidic work up to give the desired product in its hydrate form (10a) in 60\% yield. The hydrate $\mathbf{1 0 a}$ can be partly converted to the ketone (10b) by bulb-to-bulb distillation (ratio 10a:10b after distillation $=1: 1.1)$.

The final deprotection was a two-step process. First, the phosphonic acid moiety was deprotected using TMSBr/allylTMS for $24 \mathrm{~h}$ at $60^{\circ} \mathrm{C}$. The relatively high temperature and long reaction time were necessary due to the large electron withdrawing effect of the $\mathrm{CF}_{2}$ group. Next, the ester was saponified at $\mathrm{pH}>10$ in aqueous $\mathrm{NaOH}$, and the final product passed through Dowex 50Wx8, $\mathrm{H}^{+}$form, in order to remove excess base. The $\mathrm{pH}$ was adjusted to 7 using aqueous $\mathrm{NaOH}$ and the sodium salt of $\mathbf{4}$ was isolated by lyophilisation as a colorless powder. 


\subsection{Expression, purification and kinetic characterization of BfPnPDC}

The expression and purification of the C-terminal His-tagged BfPnPDC proceeded smoothly and in good yield. The steady state kinetics of $B f P n P D C$ were determined using a modified coupled assay. ${ }^{12,23}$ In a typical assay for a pyruvate decarboxylase (PDC), the coupling enzyme is a yeast alcohol dehydrogenase (YADH), that catalyzes the reduction of acetaldehyde and the concomitant oxidation of NADH, thus allowing the reaction to be followed spectrophotometrically at $340 \mathrm{~nm}$. Phosphonoacetaldehyde (3), the product of the BfPnPDC reaction, is not a substrate for YADH. However, the phosphono group can be removed by phosphonoacetaldehyde hydrolase (Phtase) which then allows further reaction with YADH. Accordingly, the Phtase from P. putida was also expressed and affinity purified. Its utility in the coupled assay was verified using authentic phosphonoacetaldehyde and YADH.

The his-tagged BfPnPDC exhibited Michaelis-Menten type kinetics with its natural substrate, phosphonopyruvate, with no evidence of the allosteric activity often observed with the yeast pyruvate decarboxylases. ${ }^{24,25}$ The $K_{\mathrm{m}}$ value was determined to be $2.9 \pm 0.2 \mu \mathrm{M}$ with a $k_{\text {cat }}$ value of $10.1 \pm 0.3 \mathrm{~s}^{-1}$. These values are in excellent agreement with those measured for the untagged enzyme. ${ }^{12}$ The PnPDC from Streptomyces viridochromogenes Tü494 had a similar $K_{\mathrm{m}}$ value but a 10-fold lower value for $k_{\text {cat }}{ }^{23}$ Overall, the data provide a $k_{\text {cat }} / K_{\mathrm{m}}$ of $3500 \mathrm{mM}^{-1} \mathrm{~s}^{-1}$ for the reaction of BfPnPDC with its natural substrate. By comparison, PDC from Zymomonas mobilis has a $k_{\text {cat }} / K_{\mathrm{m}}$ value for pyruvate of $440 \mathrm{mM}^{-1} \mathrm{~s}^{-1},{ }^{26} \sim 8$-fold lower, while at $45 \mathrm{mM}^{-1} \mathrm{~s}^{-1}$, Saccharomyces cerevisiae PDC has a $k_{\text {cat }} / K_{\mathrm{m}}$ value almost 80 -fold lower than that of $B f \mathrm{PnPDC} .{ }^{27}$ It has been suggested that much of the difference in catalytic efficiency results from the presence of the "phosphono" group which is the major source of enzyme-substrate binding energy. ${ }^{12}$ 


\subsection{Reaction of PnDFP with BfPnPDC}

In control experiments the inhibitor was tested against both Phtase and YADH. No inhibition was observed. By contrast, PnDFP proved to be an excellent inhibitor of BfPnPDC. The low $K_{\mathrm{m}}$ value for phosphonopyruvate precluded standard inhibition assays so $I C_{50}$ values were obtained at phosphonopyruvate concentrations of $3 \mu \mathrm{M}\left(\sim K_{\mathrm{m}}\right)$ and $30 \mu \mathrm{M}\left(10 \times K_{\mathrm{m}}\right)$. Using the ChengPrusoff equation the $K_{\mathrm{i}}$ value for PnDFP was determined to be $0.60 \pm 0.05 \mu \mathrm{M}$.

\subsubsection{PnDFP irreversibly inactivates BfPnPDC}

To determine if the inhibition was (i) time-dependent and (ii) irreversible, a dilution study was performed. A mixture of enzyme $(6 \mu \mathrm{M})$ and $4(50 \mu \mathrm{M})$ was incubated at $30^{\circ} \mathrm{C}$ before an aliquot was diluted 1:100 into an assay mixture containing saturating PnP. No activity was observed at any of the time points tested. Reducing the inhibitor concentration to $10 \mu \mathrm{M}$ gave similar results. Further, no enzyme activity was recovered after overnight dialysis. Taken together this indicates that the inhibitor binds both rapidly and, in effect, irreversibly.

\subsubsection{Titration of BfPnPDC with PnDFP monitored by UV-Vis spectroscopy.}

The first step in the reaction of ThDP-dependent enzymes is generally the formation of a covalent nucleophilic adduct between the $\mathrm{C} 2$ atom of the thiazolium ring of ThDP and the carbonyl group of the substrate. ${ }^{28}$ The reaction continues via a series of covalently bound ThDPcomplexes, many of which can be observed by both UV spectrophotometry and circular dichroism (CD) spectrosopy. ${ }^{29}$ Assuming PnDFP is a mechanism-based inhibitor of BfPnPDC (Scheme 2), it may be expected that titration of the inhibitor would provide a "signature" UV or CD signal. This proved to be true as the addition of PnDFP to the enzyme resulted in a yellow color. 


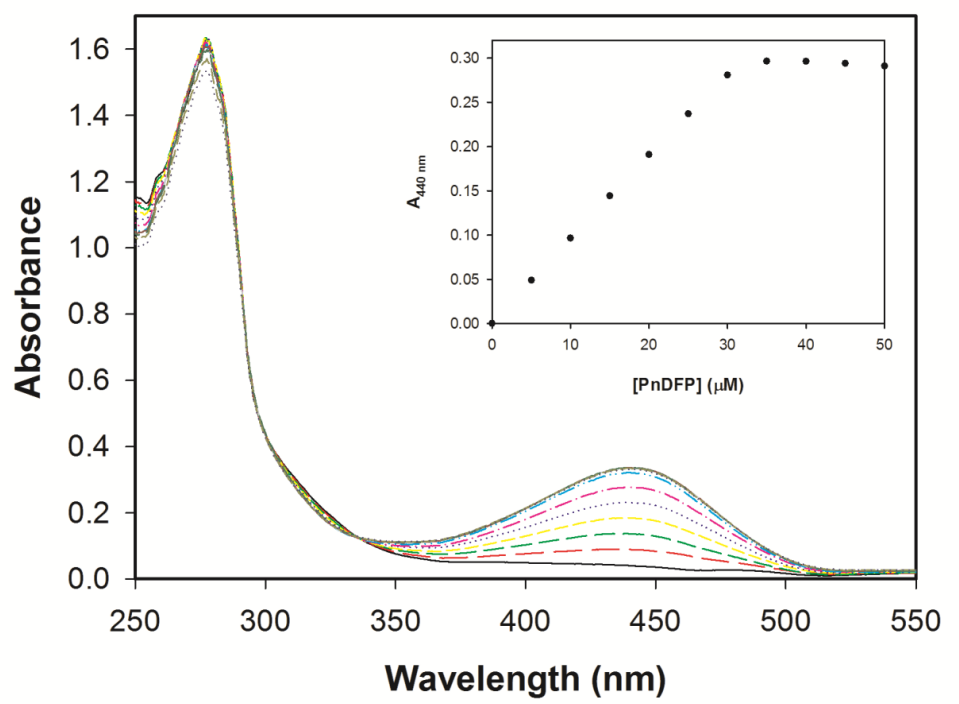

Figure 1. The titration of BfPnPDC $(\sim 50 \mu \mathrm{M})$ with PnDFP (4) monitored by UV-Vis spectroscopy. The peak at $280 \mathrm{~nm}$ is due to ThDP.

Accordingly the titration of BfPnPDC $(\sim 50 \mu \mathrm{M})$ with $4(0-50 \mu \mathrm{M})$ was monitored via UVVisible spectrophotometry and it was found that the color change was reflected in an increase in absorbance at $440 \mathrm{~nm}$ (Figure 1). The intensity increased linearly until a plateau was reached at around $35 \mu \mathrm{M}$ inhibitor (see inset Figure 1), suggesting that (i) the enzyme was saturated with inhibitor and (ii) the concentration of enzyme may be lower than expected on the basis of Bradford measurements. The latter is not unexpected as variation in concentrations arising from the Bradford method are common. ${ }^{30}$ Unfortunately, interference due to the presence of ThDP in the storage buffers renders $\mathrm{OD}_{280}$ measurements even less reliable.

2.3.3 Titration of BfPnPDC with PnDFP monitored by CD spectropolarimetry.

$\mathrm{CD}$ was also used to monitor a similar titration of BfPnPDC with 4, with results shown in Figure 2. Two maxima were observed. The first, around $315 \mathrm{~nm}$, has been attributed to formation of the 1',4'-iminopyrimidine tautomer of enzyme-bound $\mathrm{ThDP}^{29,31}$ or intermediates related to 
C2 $\alpha$-adducts of ThDP. ${ }^{32-34}$ The second maximum, around $440 \mathrm{~nm}$, has been attributed to formation of a charge transfer band, likely arising from an interaction of a $\pi$ bond on the $\mathrm{C} 2$ sidechain of ThDP and the positively charged thiazolium ring as donor and acceptor, respectively. ${ }^{29}$ As with the UV data, the CD data at $440 \mathrm{~nm}$ showed a linear increase with inhibitor concentration, again with a plateau around $35 \mu \mathrm{M}$ inhibitor (Figure S1).

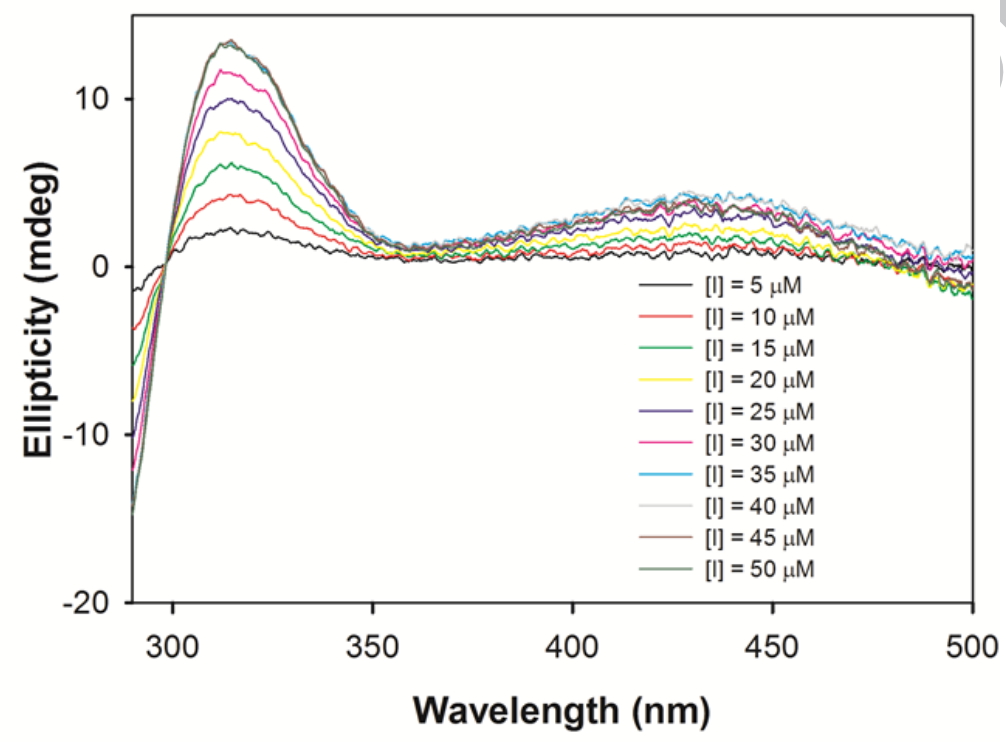

Figure 2. The titration of $B f P n P D C(\sim 50 \mu \mathrm{M})$ with PnDFP (4) monitored by CD spectropolarimetry.

\subsection{Reaction of PnDFP with BfPnPDC releases fluoride ion.}

The postulated mechanism for the reaction of PnDFP with the ThDP of BfPnPDC (Scheme 2) requires the elimination of a fluoride ion. To test this hypothesis, a fluoride ion-selective probe was used to analyze the products of the titration of the enzyme $(\sim 100 \mu \mathrm{M})$ with PnDFP $(100$ $\mathrm{mM})$. Figure 3 shows a linear relationship between added 4 and release of fluoride ion. This 1:1 relationship is clear over the range $0-50 \mu \mathrm{M} \mathrm{4}$, but tapers off around $75 \mu \mathrm{M}$. This value is 
consistent with that obtained for UV-Vis and CD studies, again suggesting that the concentration of enzyme may be lower than anticipated.

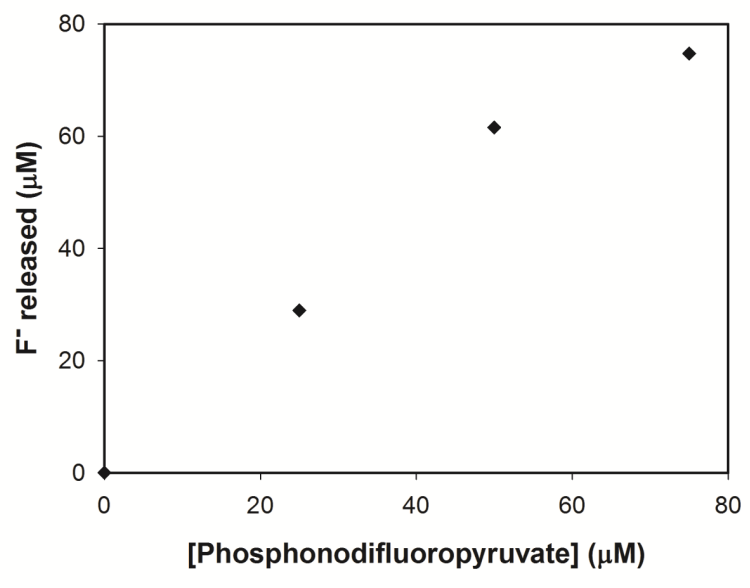

Figure 3: Fluoride ion analysis of the titration of PnPDC $(\sim 100 \mu \mathrm{M})$ with $\operatorname{PnDFP}(4)$.

\subsection{Screening for crystals of BfPnPDC}

Attempts were made to crystallize BfPnPDC in the presence and absence of 4 . All attempts were unsuccessful. 


\section{Discussion}

Biosynthesis of phosphonates is important to many pathogenic organisms. ${ }^{12,14-16}$ Given that they are not produced in higher plants, animals and humans, it seemed as though the phosphonate biosynthetic pathway would be worth exploring as a target for novel antibiotics. An important consideration is that two enzymes, PEP mutase and PnPDC, catalyze the first two steps in the biosynthesis of virtually all known phosphonates (Scheme 1). Accordingly, by focusing on these enzymes it is possible to envisage a general strategy to interfere with all phosphonate biosynthesis. PnPDC was chosen as our initial target as it (i) carries out an irreversible biosynthetic step and (ii) is of fundamental interest in that it is thought to closely resemble the fused domain common ancestor of all ThDP-dependent enzymes. ${ }^{35,36}$ To date, only two PnPDCs, those from Bacteroides fragilis (BfPnPDC) ${ }^{12}$ and Streptomyces viridochromogenes Tü494 (SvPnPDC $)^{23}$ have been fully characterized. The former is from a human pathogen while the latter organism produces the natural herbicide bialaphos and the antibiotic, streptazolin. Another PnPDC, that from Streptomyces hygroscopicus, has been purified but not well characterized. ${ }^{37}$ Confusingly, gel filtration analysis has suggested that the native enzymes existed as a homotrimer, a homodimer and a homotetramer, respectively. The oligomeric status could be clarified by an X-ray structure but, as yet, no PnPDC has been crystallized. It was hoped that formation of an inhibitor:ThDP adduct may facilitate crystallization, as has been observed for other ThDP enzymes such as benzoylformate decarboxylase ${ }^{33,38}$ and benzaldehyde lyase. ${ }^{39,40}$

In the first instance we proposed that 3,3-difluoro-3-phosphonopyruvate (PnDFP, 4) would act specifically as mechanism-based inhibitor for PnPDC. To explore this possibility the sodium salt of PnDFP was synthesized in three steps from diethyl difluoromethylphosphonate (Scheme 3). An alternative strategy employing dibromodifluoromethane as the starting material ${ }^{41-45}$ was also successful, although the yields were much more variable. Concomitantly we were able to express 
and purify BfPnPDC as a C-terminal his-tagged variant, and used a coupled assay to confirm that its kinetic data were identical to that of the wild type enzyme. Testing showed that 4 was a potent inhibitor of BfPnPDC, with a $K_{\mathrm{i}}$ value in the sub-micromolar range.

Silverman ${ }^{46}$ has defined several criteria, most of which should be met by $\mathbf{4}$, in order for it to be characterized as a mechanism-based inhibitor. These include (a) time-dependent inactivation, (ii) saturation kinetics, (iii) substrate protection, (iv) irreversible inactivation, (v) 1:1 stoichiometry of binding, (vi) involvement of a catalytic step and (vii) that binding occurs at the active site. PnDFP is clearly an analogue of the substrate, PnP, and shows the qualities necessary to call it a mechanism-based inhibitor. Indeed, its reaction with BfPnPDC was sufficiently rapid to preclude the dilution assay normally used to demonstrate that time-dependent inactivation was accompanied by saturation kinetics. Nonetheless we could show that inactivation could not be reversed by either dilution or exhaustive dialysis. Increasing the substrate concentration from 3 $\mu \mathrm{M}$ to $10 \mu \mathrm{M}$ saw the $\mathrm{IC}_{50}$ value increase from 1.3 to $14 \mu \mathrm{M}$, thereby satisfying the criterion of substrate protection.

Titration of the enzyme with PnDFP resulted in the formation of a yellow color which could be monitored at $440 \mathrm{~nm}$ by both UV-Vis spectrophotometry (Figure 1) and CD spectroscopy (Figure 2). Both methods provided clear evidence of a 1:1 relationship between enzyme and inhibitor concentration. A similar color was observed by Merski and Townsend ${ }^{47}$ during the reaction of D-glyceraldehyde-3-phosphate with N2-(2-carboxyethyl)arginine synthase, a ThDPdependent enzyme involved in clavulanic acid biosynthesis. In that instance the yellow chromophore was attributed to the formation of an acryloyl-ThDP adduct, which is not dissimilar to the adduct predicted for PnPDC in Scheme 2. ${ }^{47}$ In addition to the maximum at $440 \mathrm{~nm}$, the CD spectra showed a second maximum at $315 \mathrm{~nm}$. There are several instance where the Jordan group has demonstrated that this band arises from formation of the 1',4'-iminopyrimidine tautomer of 
enzyme-bound ThDP or enzyme bound C2 $\alpha$-adducts of ThDP. ${ }^{29,31-34}$ Thus, observation of the band at $315 \mathrm{~nm}$ provides further evidence for $\mathbf{4}$ binding at the active site.

Perhaps the most important criterion for a mechanism-based inhibitor is the involvement of a catalytic step. For 4 we were able to confirm this by using an ion-selective electrode to establish that enzyme inactivation was accompanied by the release of a fluoride ion. Figure 3 shows that, when BfPnPDC was titrated with 4, there was a 1:1 relationship between the concentration of free $\mathrm{F}^{-}$and added inhibitor. Taken together, all data point to PnDFP being a potent mechanismbased inhibitor of phosphonopyruvate decarboxylase. At this time it is not clear which ThDP complex (7 or $\mathbf{8}$, Scheme 2) is responsible for the inhibition, and analogues of both keto and enol complexes have been reported on ThDP-dependent enzymes. ${ }^{29}$ It is notable that $\mathbf{8}$ is an analogue of acetylthiamin diphosphate which may expected to be hydrolyzed. Two observations mitigate against this. First, there is no rapid loss of the absorbance at $440 \mathrm{~nm}$ and second, there is no rapid regeneration of active enzyme. It appears that, while acylthiamin diphosphate intermediates can hydrolyze rapidly on some enzymes, on others, such as pyruvate oxidase ${ }^{48}$ and benzoylformate decarboxylase $^{49}$, it can be quite slow. PnPDC would seem to fit into the latter category. Another possibility is that the equilibrium lies in favor of $\mathbf{8}$, which is subsequently attacked by an active site nucleophile. Such a mechanism was proposed for the inactivation of the E1 subunit of the pyruvate dehydrogenase complex. ${ }^{22}$ It was hoped that this issue could be resolved by crystallography but, unfortunately, X-ray quality crystals are not yet available. Screening for suitable conditions is continuing.

While inhibition of PnPDC is the prime focus of this paper, it must be remembered that PnP is also a substrate of PEP mutase (Scheme 1). There remains the possibility that 4 could be converted into difluoroPEP and, given that monofluoroPEP inhibits several PEP utilizing enzymes, ${ }^{50}$ there is a good chance that difluoroPEP would behave similarly. Even assuming that 
difluoroPEP acts as a substrate for the PEP enzymes, subsequent transformations would result in the formation of fluorinated pyruvate analogs which are also toxic. It is also important to note that PEP mutase is not found in higher organisms and, therefore, no fluorinated PEP or subsequent products will be formed in mammalian cells. Given this, and the success of $\mathbf{4}$ as a PnPDC inhibitor, future work will focus on the development of $\mathbf{4}$ as an in vivo inhibitor of phosphonate biosynthesis. 


\section{Experimental section}

\subsection{General methods}

A plasmid (bf-Pyrdecarb-pET3A) ${ }^{12}$ containing recombinant phosphonopyruvate decarboxylase from Bacteroides fragilis (BfPnPDC)was a gift of Dr. Debra Dunaway-Mariano (University of New Mexico, Albuquerque, NM). A plasmid containing recombinant C-terminal His-tagged phosphonoacetaldehyde hydrolase (Phtase) from Pseudomonas putida (pET22Phtase-His) ${ }^{23}$ was a gift of Prof. Georg A. Sprenger (University of Stuttgart, Germany).

${ }^{1} \mathrm{H},{ }^{13} \mathrm{C},{ }^{19} \mathrm{~F}$ and ${ }^{31} \mathrm{P}$ NMR spectra were measured in $\mathrm{CDCl}_{3}$ or $\mathrm{D}_{2} \mathrm{O}$ on a Bruker Avance 400 $\left({ }^{1} \mathrm{H}: 400.27 \mathrm{MHz},{ }^{13} \mathrm{C}: 100.65 \mathrm{MHz},{ }^{19} \mathrm{~F}: 376.50 \mathrm{MHz},{ }^{31} \mathrm{P}: 162.03 \mathrm{MHz}\right)$ or DRX $400\left({ }^{1} \mathrm{H}:\right.$ 400.13 MHz, $\left.{ }^{13} \mathrm{C}: 100.61 \mathrm{MHz},{ }^{31} \mathrm{P}: 161.98 \mathrm{MHz}\right)$ spectrometer as indicated. The chemical shifts were referenced to residual $\mathrm{CHCl}_{3}\left(\delta_{\mathrm{H}} 7.24\right), \mathrm{HOD}\left(\delta_{\mathrm{H}} 4.80\right) ; \mathrm{CDCl}_{3}\left(\delta_{\mathrm{C}} 77.23\right)$ external $\mathrm{H}_{3} \mathrm{PO}_{4}$ $(85 \%)\left(\delta_{\mathrm{P}} 0.00\right)$ and $\mathrm{FCCl}_{3}\left(\delta_{\mathrm{F}} 0.00\right)$. Chemical shifts $(\delta)$ are given in ppm and coupling constants $(J)$ in Hz. IR spectra were recorded on a Bruker VERTEX 70 IR spectrometer in ATR mode. Spectra for compounds $\mathbf{4}$ and $\mathbf{1 0 a}$ are provided as supplementary material.

TLC was usually carried out on $0.25 \mathrm{~mm}$ thick Merck plates precoated with silica gel $60 \mathrm{~F}_{254}$. Spots were visualised by UV and/or dipping the plate into a solution of $\left(\mathrm{NH}_{4}\right)_{6} \mathrm{Mo}_{7} \mathrm{O}_{24} \cdot 4 \mathrm{H}_{2} \mathrm{O}$ $(25.0 \mathrm{~g})$ and $\mathrm{Ce}\left(\mathrm{SO}_{4}\right)_{2} \cdot 4 \mathrm{H}_{2} \mathrm{O}(1.0 \mathrm{~g})$ in $10 \%$ aqueous $\mathrm{H}_{2} \mathrm{SO}_{4}(500 \mathrm{~mL})$, followed by heating with a heat gun. Flash (column) chromatography was performed with Merck silica gel 60 (230-400 mesh).

Diethyl difluoromethylphosphonate, bromotrimethylsilane, allyltrimethylsilane and diethyl oxalate were from Sigma Aldrich. THF was refluxed over potassium and distilled prior to use. Authentic samples of $\mathrm{PnP}$ (2) and PnAA (3) were prepared as their sodium salts using variations 
on established methods. Details are provided in the supplementary material. All other chemicals and buffer components were used as purchased from Sigma-Aldrich, Acros, Fluka or Merck.

\subsubsection{Ethyl 3-(diethoxyphosphoryl)-3,3-difluoro- 2,2-dihydroxy-propanoate (10a): ${ }^{\mathbf{5 1}}$}

$n \operatorname{BuLi}$ (3.1 mmol, $1.24 \mathrm{~mL}, 2.5 \mathrm{M}$ solution in hexanes) was added dropwise to a solution of $i \mathrm{Pr}_{2} \mathrm{NH}(334 \mathrm{mg}, 3.3 \mathrm{mmol}, 0.46 \mathrm{~mL})$ in dry THF $(3 \mathrm{~mL})$ at $-40{ }^{\circ} \mathrm{C}$ under argon. The mixture was stirred at this temperature for $15 \mathrm{~min}$ and afterwards cooled to $-95^{\circ} \mathrm{C}$. Diethyl difluoromethylphosphonate $(600 \mathrm{mg}, 3.1 \mathrm{mmol}, 0.50 \mathrm{~mL})$, dissolved in dry THF $(3 \mathrm{~mL})$ was added dropwise and the resulting solution was stirred for 5 min at the same temperature. Diethyl oxalate (453 mg, $3.1 \mathrm{mmol}, 0.42 \mathrm{~mL})$ dissolved in dry THF (3 mL) was added and the solution was allowed to warm to $-78^{\circ} \mathrm{C}$ in the cooling bath, whereupon it turned pale yellow. Upon addition of glacial acetic acid (186 mg, $3.1 \mathrm{mmol}, 0.17 \mathrm{~mL})$ the solution became colourless again. After extraction with $\mathrm{NaHCO}_{3}$ solution $(3 \times 10 \mathrm{~mL}$, sat.) the combined aqueous phases were washed with EtOAc $(2 \times 10 \mathrm{~mL})$, were dried $\left(\mathrm{Na}_{2} \mathrm{SO}_{4}\right)$ and concentrated in vacuo. The crude product was purified by bulb-to-bulb distillation $\left(105-115^{\circ} \mathrm{C} / 0.49 \mathrm{mbar}\right)$ to give a pale yellow, viscous liquid (569 mg, 60\%). Subsequent flash chromatography (ethyl acetate $($ EtOAc $) /$ hexanes $\left.=2: 1, R_{\mathrm{f}}=0.44\right)$ yielded the difluorinated phosphonate in its hydrate form (10a) as a colourless oil; ${ }^{1} \mathrm{H}$ NMR $\left(\mathrm{CDCl}_{3}, 400.13 \mathrm{MHz}\right): \delta 5.15(b r \mathrm{~s}, 1.5 \mathrm{H}, 2$ x OH$), 4.37$ (q, $J$ $\left.=7.2 \mathrm{~Hz}, 2 \mathrm{H}, \mathrm{C}(\mathrm{O}) \mathrm{OCH}_{2}\right), 4.38-4.24\left(\mathrm{~m}, 4 \mathrm{H}, 2 \times \mathrm{P}(\mathrm{O}) \mathrm{OC}_{2}\right), 1.37\left(\mathrm{td}, J_{\mathrm{HH}}=7.1 \mathrm{~Hz}, J_{\mathrm{HP}}=0.7\right.$ $\left.\mathrm{Hz}, 6 \mathrm{H}, 2 \times \mathrm{CH}_{3}\right), 1.35\left(\mathrm{t}, J=7.2 \mathrm{~Hz}, 3 \mathrm{H}, \mathrm{C}(\mathrm{O}) \mathrm{CH}_{2} \mathrm{C}_{3}\right) ;{ }^{13} \mathrm{C} \mathrm{NMR}\left(\mathrm{CDCl}_{3}, 100.61 \mathrm{MHz}\right): \delta$ $167.45\left(\mathrm{~d}, J_{\mathrm{CP}}=10.9 \mathrm{~Hz}, \mathrm{C}=\mathrm{O}\right), 115.77\left(\mathrm{td}, J_{\mathrm{CP}}=198.8 \mathrm{~Hz}, J_{\mathrm{CF}}=275.4 \mathrm{~Hz}, \mathrm{CF}_{2}\right), 92.76\left(\mathrm{td}, J_{\mathrm{CP}}=\right.$ 12.6 Hz, $\left.J_{\mathrm{CF}}=27.4 \mathrm{~Hz}, \mathrm{C}(\mathrm{OH})_{2}\right), 65.95\left(\mathrm{~d}, J_{\mathrm{CP}}=6.6 \mathrm{~Hz}, 2 \times \mathrm{OCH}_{2}\right), 64.24\left(\mathrm{~s}, \mathrm{OCH}_{2}\right), 16.50(\mathrm{~d}$, $\left.J_{\mathrm{CP}}=5.9 \mathrm{~Hz}, 2 \times \mathrm{CH}_{3}\right), 14.13\left(\mathrm{~s}, \mathrm{CH}_{3}\right) ;{ }^{31} \mathrm{P} \mathrm{NMR}\left(\mathrm{CDCl}_{3}, 161.98 \mathrm{MHz}\right): \delta 6.90\left(\mathrm{t}, J_{\mathrm{PF}}=95.1 \mathrm{~Hz}\right)$; ${ }^{19} \mathrm{~F} \mathrm{NMR}\left(\mathrm{CDCl}_{3}, 376.50 \mathrm{MHz}\right): \delta-120.68\left(\mathrm{~d}, J_{\mathrm{PF}}=95.1 \mathrm{~Hz}\right)$; IR (ATR): $v=3275,2989,1744$, 
1393, 1370, 1249, 1158, 1085, $1013 \mathrm{~cm}^{-1}$; Anal. calc. for $\mathrm{C}_{9} \mathrm{H}_{17} \mathrm{~F}_{2} \mathrm{O}_{7} \mathrm{P}(306.20)$ : C 35.50\%, H 5.60\%, F 12.41\%; found: C 35.31\%, H 5.49\%, F $12.16 \%$.

\subsubsection{3,3-Difluoro-2,2-dihydroxy-3-phosphonopropanoic acid (4 as its sodium salt):}

Ethyl 3-(diethoxyphosphoryl)-3,3-difluoro-2-oxo-propanoate (10, $0.153 \mathrm{~g}, 0.5 \mathrm{mmol})$ was dissolved in dry 1,2-dichloroethane (DCE, $5 \mathrm{~mL}$ ) under argon at room temperature.

Allyltrimethylsilane $(0.114 \mathrm{~g}, 1.0 \mathrm{mmol}, 0.16 \mathrm{~mL})$ and bromotrimethylsilane $(0.459 \mathrm{~g}, 3.0 \mathrm{mmol}$, $0.40 \mathrm{~mL}$ ) were added quickly one after the other and the reaction mixture was heated at $60{ }^{\circ} \mathrm{C}$ for $23 \mathrm{~h}$. Then, all volatile compounds were removed in vacuo at room temperature. DCE $(5 \mathrm{~mL})$ was added and volatiles were removed a second time; first at room temperature and then at $40{ }^{\circ} \mathrm{C}$. The residue was dried in vacuo for $2 \mathrm{~h}$ and then dissolved in water $(2 \mathrm{~mL})$. The $\mathrm{pH}$ of the solution was adjusted to 10 and it was stirred at room temperature for 1 hour. Excess base was then removed by ion exchange chromatography (Dowex $50 \mathrm{Wx} 8, \mathrm{H}^{+}$form, $12 \mathrm{~mL}$, water as eluent). All acidic fractions were collected, neutralised ( $\mathrm{pH}$ 7.1) with aqueous $\mathrm{NaOH}$ solution $(0.5 \mathrm{M})$ and finally lyophilised to give a white powder of 3,3-difluoro-2,2-dihydroxy-3phosphonopropanoic acid (4) as its sodium salt (0.138 g, about $0.48 \mathrm{mmol}) ;{ }^{1} \mathrm{H}$ NMR $\left(\mathrm{D}_{2} \mathrm{O}\right.$, 400.13 MHz): no signals detected (despite some minimal impurities which can be quantified by means of an internal standard); ${ }^{13} \mathrm{C}$ NMR $\left(\mathrm{D}_{2} \mathrm{O}, 100.61 \mathrm{MHz}\right): \delta 173.84(\mathrm{~s}, \mathrm{C}=\mathrm{O}), 118.77\left(\mathrm{td}, J_{\mathrm{CP}}\right.$ $\left.=166.7 \mathrm{~Hz}, J_{\mathrm{CF}}=270.3 \mathrm{~Hz}, \mathrm{CF}_{2}\right), \mathrm{C}-2$ signal of hydrate was not detected; ${ }^{31} \mathrm{P} \mathrm{NMR}\left(\mathrm{D}_{2} \mathrm{O}, 161.98\right.$ $\mathrm{MHz}): \delta 6.30\left(\mathrm{t}, J_{\mathrm{PF}}=80.1 \mathrm{~Hz}\right) ;{ }^{19} \mathrm{~F} \mathrm{NMR}\left(\mathrm{D}_{2} \mathrm{O}, 376.50 \mathrm{MHz}\right): \delta-122.01\left(\mathrm{~d}, J_{\mathrm{PF}}=80.1 \mathrm{~Hz}\right)$.

\subsection{Expression and purification of phosphonopyruvate decarboxylase, phosphonoacetaldehyde} hydrolase and acetolactate synthase. 
The QuikChange site-directed mutagenesis kit (Stratagene) was used to replace the stop codon of $B f \mathrm{PnPDC}$ with a $X h o 1$ restriction site. Subsequently the NdeI-XhoI fragment containing the modified BfPnPDC gene was inserted into pET24b (Novagen) to give the expression vector, pET24bBfPnPDC-His. The fidelity of the amplification and the presence of the changed nucleotides was confirmed by sequencing (University of Michigan DNA Sequencing Core Facility).

Following transformation of the plasmids, pET24bBfPnPDC-His and pET22Phtase-His into $E$. coli BL21(DE3) cells, expression and purification of the enzymes was achieved using routine procedures. ${ }^{52}$ The enzymes were quantitated with the Bradford method ${ }^{53}$ using bovine serum albumin as the standard before being concentrated to $\sim 15 \mathrm{mg} / \mathrm{mL}$. BfPnPDC was stored at $-80{ }^{\circ} \mathrm{C}$ and Phtase was stored at $4{ }^{\circ} \mathrm{C}$ in $50 \mathrm{mM}$ HEPES (pH 8.0) containing $300 \mathrm{mM} \mathrm{NaCl}, 10 \mathrm{mM}$ $\mathrm{MgCl}_{2}$, and $1 \mathrm{mM}$ DTT.

\subsubsection{Steady-state kinetic analysis of phosphonopyruvate decarboxylase}

The activity of purified BfPnPDC was determined using a coupled assay. The assay mixture contained, in a total of $1 \mathrm{~mL}, 100 \mathrm{mM}$ HEPES (pH 7.0) $5 \mathrm{mM} \mathrm{MgCl}_{2}, 0.2 \mathrm{mM} \mathrm{NADH}, 60 \mathrm{U} / \mathrm{mL}$ YADH, $100 \mu \mathrm{g}$ phosphonoacetaldehyde hydrolase, and varying concentrations of phosphonopyruvate $(0.5-15 \mu \mathrm{M})$. The reaction was carried out at $30{ }^{\circ} \mathrm{C}$ and initiated by the addition of BfPnPDC. Each assay was performed in triplicate. The kinetic parameters were determined by fitting the initial rate data to the Michaelis-Menten equation using the enzyme kinetics package from SigmaPlot 12.3.

\subsubsection{Determination of $I C_{50}$ and $K_{i}$ values for difluorophosphonopyruvate}


Here the standard assay was used with the concentration of phosphonopyruvate held constant at $3 \mu \mathrm{M}\left(\sim K_{\mathrm{m}}\right)$ or $30 \mu \mathrm{M}\left(10 \times K_{\mathrm{m}}\right)$ while the concentration of 4 was varied. The $I C_{50}$ value was determined by plotting the concentration of inhibitor $(\mu \mathrm{M})$ against residual activity. The $K_{\mathrm{i}}$ was determined from the $I C_{50}$ value using the Cheng-Prusoff equation (Equation 1).

$$
K_{\mathrm{i}}=I C_{50} /\left(1+([\mathrm{S}]) / K_{\mathrm{m}}\right)
$$

\subsubsection{Time-dependent inactivation of BfPnPDC}

BfPnPDC $(6 \mu \mathrm{M})$ and $4(10 \mu \mathrm{M}$ or $50 \mu \mathrm{M})$ were mixed in $50 \mathrm{mM}$ HEPES (pH 8.0) containing $300 \mathrm{mM} \mathrm{NaCl}, 10 \mathrm{mM} \mathrm{MgCl}$, and $1 \mathrm{mM} \mathrm{DTT}$ and incubated at $30^{\circ} \mathrm{C}$. At appropriate time intervals, an aliquot $(10 \mu \mathrm{L})$ was diluted 1:100 into a standard assay mixture containing $30 \mu \mathrm{M}$ (i.e., saturating) phosphonopyruvate.

\subsection{Reaction of phosphonodifluoropyruvate with BfPnPDC monitored by UV-VIS} spectrophotometry and circular dichroism (CD) spectropolarimetry

BfPnPDC $(\sim 50 \mu \mathrm{M})$, in a $2 \mathrm{~mL}$ volume of BfPnPDC storage buffer, was titrated with 4 at concentrations ranging from $0-50 \mu \mathrm{M}$. PnDFP was introduced in $10 \mu \mathrm{L}$ aliquots with each addition resulting in a $5 \mu \mathrm{M}$ increase in inhibitor concentration. Spectra were obtained using a 1 $\mathrm{cm}$ path length cell. After the addition of each of the inhibitor aliquots, the solution was gently mixed and allowed to sit for a minimum of 3 minutes at $25^{\circ} \mathrm{C}$. The reaction mixtures were monitored on a Cary 50 Bio UV-Vis spectrophotometer at $440 \mathrm{~nm}$ to ensure the reaction was complete, before a scan was recorded from $550-250 \mathrm{~nm}$. The $\mathrm{Abs}_{440}$ titration curves were constructed using SigmaPlot 12.3. 
The procedure was repeated using the Jasco J-810 CD spectropolarimeter. The reaction was initially monitored at $440 \mathrm{~nm}$ on a UV-VIS spectrophotometer to ensure the reaction was complete. Subsequently the mixture was then scanned from $550-250 \mathrm{~nm}$ on the CD spectropolarimeter. The data obtained for each inhibitor concentration was the average of five individual scans. Titration curves for the change in ellipticity at $440 \mathrm{~nm}$ were constructed using SigmaPlot 12.3.

\subsection{Fluoride ion analysis of the reaction of phosphonodifluoropyruvate with BfPnPDC}

Release of fluoride ions from the reaction of 4 with BfPnPDC was monitored using a fluoride ion-selective electrode. Samples containing BfPnPDC $(\sim 100 \mu \mathrm{M})$ were mixed with PnDFP $(0-75$ $\mu \mathrm{M}$ ) in a total volume of $1 \mathrm{~mL}$. In addition, two controls were used. The first contained BfPnPDC buffer and water, and the second contained BfPnPDC buffer, $75 \mu \mathrm{M} 4$ and water in a total volume of $1 \mathrm{~mL}$. After gentle mixing reactions were incubated at room temperature for $30 \mathrm{~min}$. The enzyme was removed from the samples using 10,000 kDa cut-off microspin columns (Microcon, Millipore). Total ionic strength adjustment buffer II solution (TISAB II) was added to the samples to a final volume of $2 \mathrm{~mL}$. The fluoride ion concentration in each sample was determined.

\subsection{Attempted crystallization BfPnPDC}

For crystallization trials the enzyme was concentrated to $15 \mathrm{mg} / \mathrm{mL}$ in $25 \mathrm{mM}$ HEPES pH 7.0, containing $0.2 \mathrm{mM}$ ThDP and $0.1 \mathrm{mM} \mathrm{MgCl}_{2}$. Screening was initiated by mixing the enzyme (in the presence and absence of 4) 1:1 with the conditions of Hampton Crystal Screen II.

\section{Acknowledgements}


We thank National Science Foundation (CHE 1306877 to MJM) and the Austrian Science Fund (P27987-N28 to FWF) for financial support. We thank Johannes Theiner for performing combustion analysis, and Susanne Felsinger for recording ${ }^{19} \mathrm{~F}$ NMR spectra. We also acknowledge the help of the Lippert laboratory at the Indiana University School of Dentistry with the fluoride ion analyses, Malea Kneen for critical reading of the manuscript, and Prof. Ron Kluger for his advice on ThDP intermediates. 


\section{References}

[1] Kamat SS, Williams HJ, Dangott LJ, Chakrabarti M, Raushel FM. Nature. 2013; 497: 132136.

[2] Yu X, Doroghazi JR, Janga SC, et al. Proc Natl Acad Sci U S A. 2013; 110: 20759-20764.

[3] Seto H, Kuzuyama T. Nat Prod Rep. 1999; 16: 589-596.

[4] Peck SC, van der Donk WA. Curr Opin Chem Biol. 2013; 17: 580-588.

[5] Horsman GP, Zechel DL. Chem Rev. 2017; 117: 5704-5783.

[6] Bowman E, McQueney M, Barry RJ, Dunaway-Mariano D. J Am Chem Soc. 1988; 110 : 5575-5576.

[7] Metcalf WW, van der Donk WA. Annu Rev Biochem. 2009; 78: 65-94.

[8] Patel SS, Balfour JA, Bryson HM. Drugs. 1997; 53: 637-656.

[9] Whitteck JT, Ni W, Griffin BM, et al. Angew Chem Int Ed Engl. 2007; 46: 9089-9092.

[10] Duke SO, Dayan FE, Romagni JG, Rimando AM. Weed Res. 2000; 40: 99-111.

[11] Morais MC, Zhang W, Baker AS, et al. Biochemistry. 2000; 39: 10385-10396.

[12] Zhang G, Dai J, Lu Z, Dunaway-Mariano D. J Biol Chem. 2003; 278: 41302-41308.

[13] Ju KS, Gao J, Doroghazi JR, et al. Proc Natl Acad Sci US A. 2015; 112: 12175-12180.

[14] Katayama N, Tsubotani S, Nozaki Y, Harada S, Ono H. J Antibiot (Tokyo). 1990; 43: 238246.

[15] Carter RF. J Pathol. 1970; 100: 217-244.

[16] Berriman M, Ghedin E, Hertz-Fowler C, et al. Science. 2005; 309: 416-422.

[17] Circello BT, Eliot AC, Lee JH, van der Donk WA, Metcalf WW. Chem Biol. 2010; 17: 402411.

[18] Walsh CT. Tetrahedron. 1982; 38: 871-909.

[19] Kluger R, Pike DC. J Am Chem Soc. 1977; 99: 4504-4506.

[20] Brammer LA, Smith JM, Wade H, Meyers CF. J Biol Chem. 2011; 286: 36522-36531.

[21] Flournoy DS, Frey PA. Biochemistry. 1989; 28: 9594-9602.

[22] Frey PA, Flournoy DS, Gruys K, Yang YS. Ann N Y Acad Sci. 1989; 573: 21-35.

[23] Johnen S, Sprenger GA. J Mol Catalysis B. 2009; 61: 39-46.

[24] Hübner G, Weidhase R, Schellenberger A. Eur J Biochem. 1978; 92: 175-181.

[25] Krieger F, Spinka M, Golbik R, Hübner G, König S. Eur J Biochem. 2002; 269: 3256-3263.

[26] Siegert P, McLeish MJ, Baumann M, et al. Prot Eng Des Sel. 2005; 18: 345-357.

[27] Li H, Jordan F. Biochemistry. 1999; 38: 10004-10012.

[28] Kluger R, Tittmann K. Chem Rev. 2008; 108: 1797-1833.

[29] Patel H, Nemeria NS, Andrews FH, McLeish MJ, Jordan F. Biochemistry. 2014; 53: 2145 2152.

[30] Lu TS, Yiao SY, Lim K, Jensen RV, Hsiao LL. N Am J Med Sci. 2010; 2: 325-328.

[31] Nemeria N, Korotchkina L, McLeish MJ, et al. Biochemistry. 2007; 46: 10739-10744.

[32] Nemeria N, Baykal A, Joseph E, et al. Biochemistry. 2004; 43: 6565-6575.

[33] Brandt GS, Kneen MM, Chakraborty S, et al. Biochemistry. 2009; 48: 3247-3257.

[34] Nemeria NS, Chakraborty S, Balakrishnan A, Jordan F. FEBS J. 2009; 276: 2432-2446.

[35] Costelloe SJ, Ward JM, Dalby PA. J Mol Evol. 2008; 66: 36-49.

[36] Duggleby RG. Acc Chem Res. 2006; 39: 550-557.

[37] Nakashita H, Watanabe K, Hara O, Hidaka T, Seto H. J Antibiot (Tokyo). 1997; 50: 212219.

[38] Chakraborty S, Nemeria NS, Balakrishnan A, et al. Biochemistry. 2009; 48: 981-994. 
[39] Brandt GS, Nemeria N, Chakraborty S, et al. Biochemistry. 2008; 47: 7734-7743.

[40] Brandt GS, Kneen MM, Petsko GA, Ringe D, McLeish MJ. J Am Chem Soc. 2009; 132: 438-439.

[41] Kawamoto AM, Campbell MM. J Chem Soc Perkin Trans 1. 1997: 1249-1253.

[42] Burton DJ, Ishihara T, Maruta M. Chem Lett. 1982; 11: 755-758.

[43] Burton DJ, LaSprague LG. J Org Chem. 1988; 53: 1523-1527.

[44] Burton DJ, LaSprague LG. J Org Chem. 1989; 54: 613-617.

[45] Tsai H-J. Phosphorus, Sulfur Silicon Relat Elem 1997; 122: 247-259.

[46] Silverman RB. Methods Enzymol. 1995; 249: 240-283.

[47] Merski M, Townsend CA. J Am Chem Soc. 2007; 129: 15750-15751.

[48] Tittmann K, Golbik R, Ghisla S, Hübner G. Biochemistry. 2000; 39: 10747-10754.

[49] Dirmaier LJ, Garcia GA, Kozarich JW, Kenyon GL. J Am Chem Soc. 1986; 108: 31493150.

[50] Garcia-Alles LF, Erni B. Eur J Biochem. 2002; 269: 3226-3236.

[51] Phillion DP, Cleary DG. J Org Chem. 1992; 57: 2763-2764.

[52] Andrews FH, Horton JD, Shin D, et al. Biochim Biophys Acta. 2015; 1854: 1001-1009.

[53] Bradford MM. Anal Biochem. 1976; 72: 248-254. 


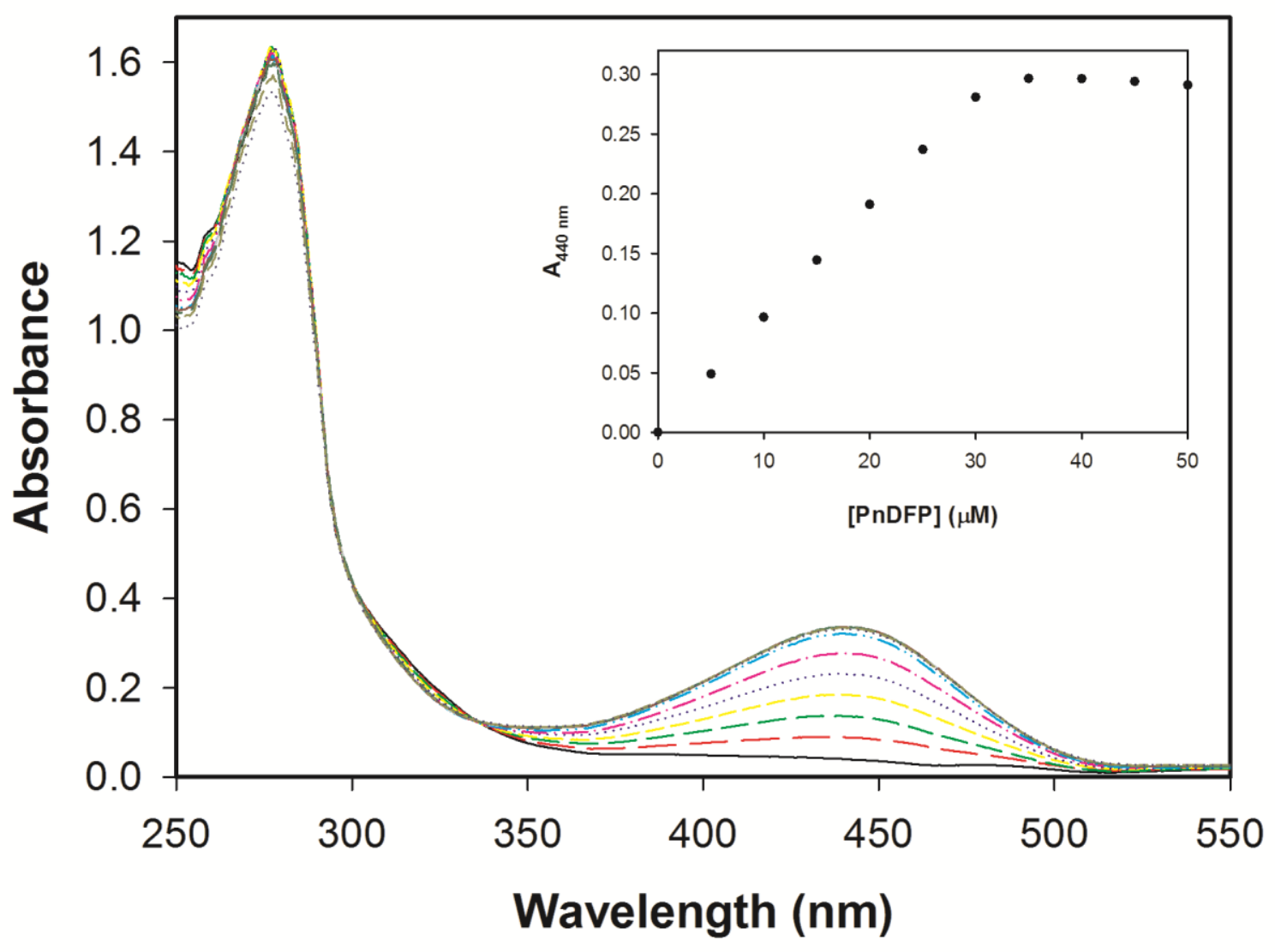




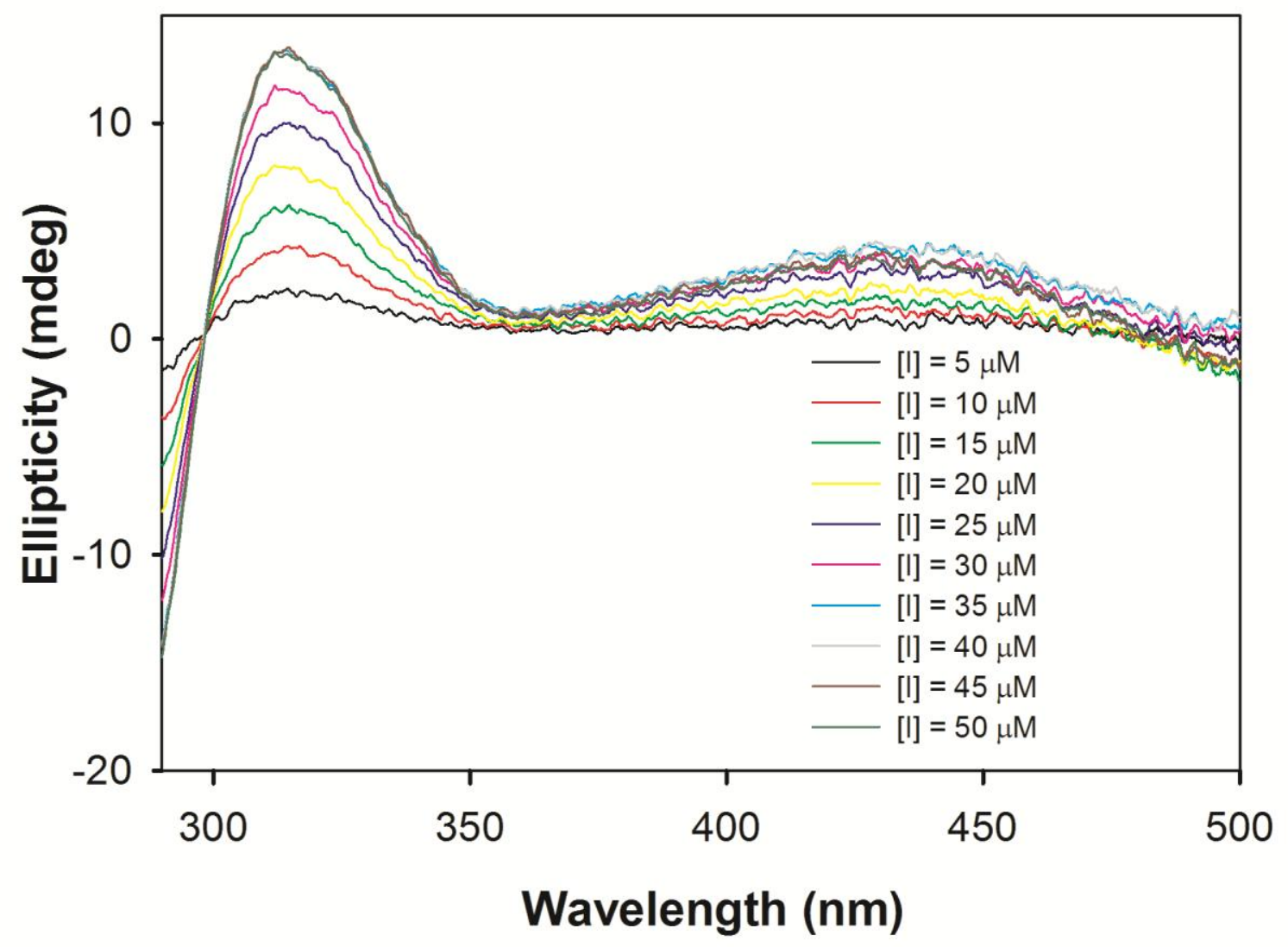




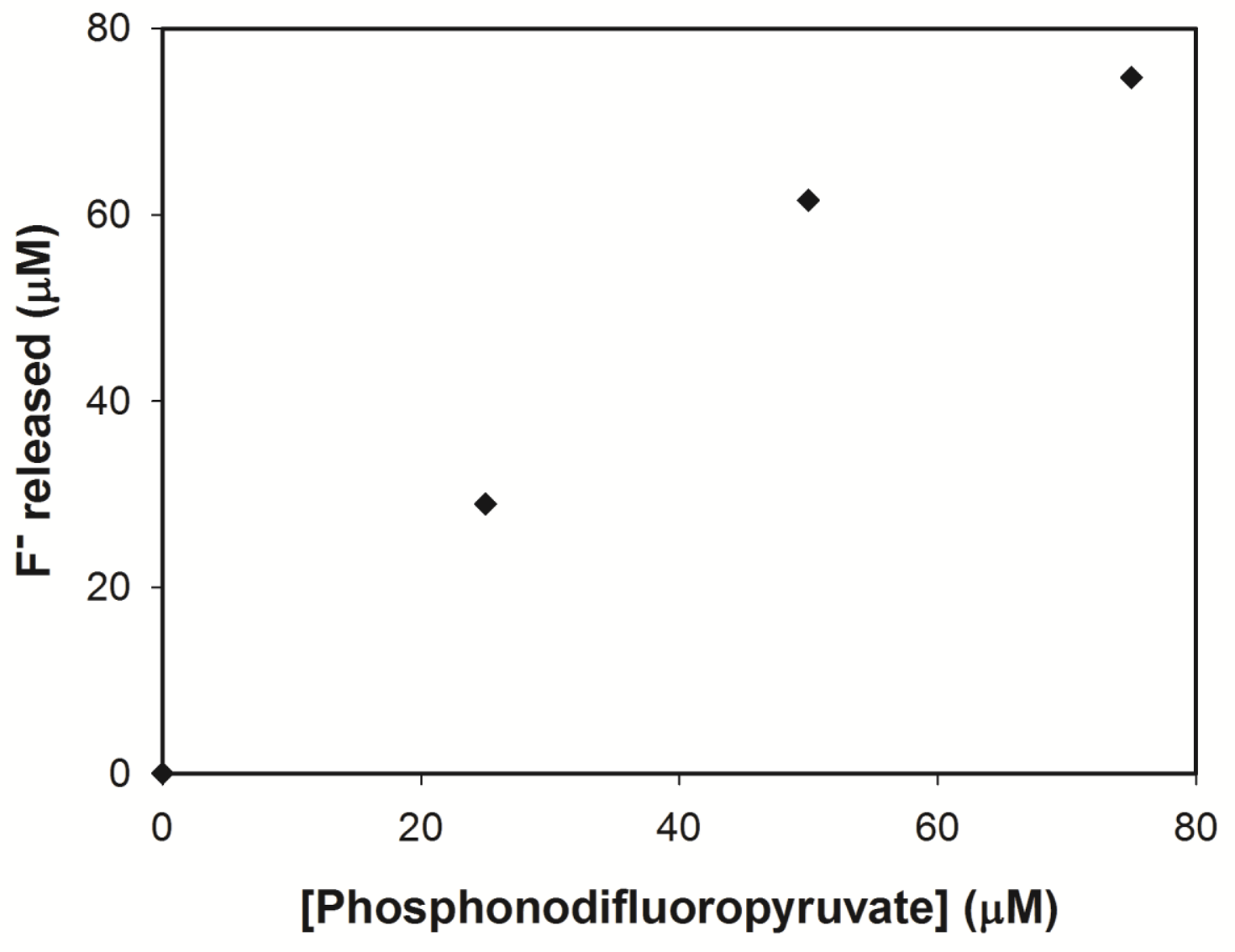




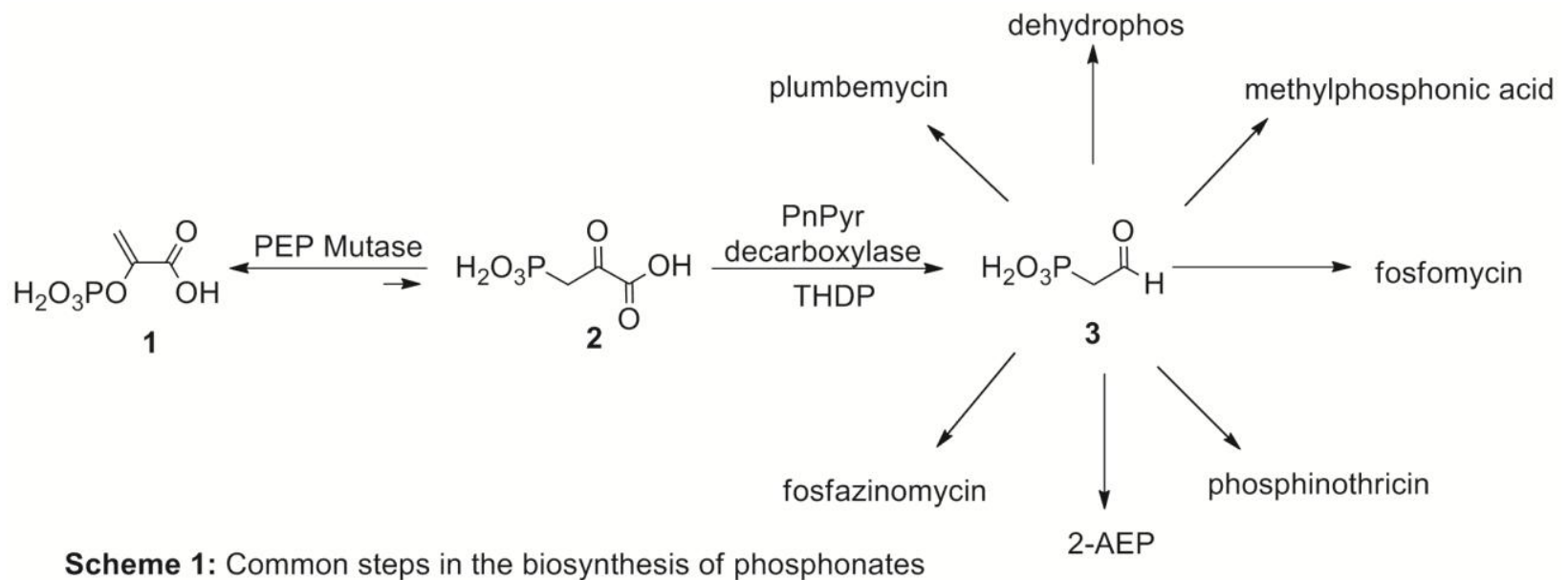

Scheme 1: Common steps in the biosynthesis of phosphonates 
<smiles>O=C(O)C(=O)C(F)(F)PO</smiles>

4<smiles>[R][n+]1[se]c(CCO[Po])c(C)c1C</smiles><smiles></smiles><smiles>CC(C)C(=O)O</smiles><smiles>[R][n+]1c(C(O)C(F)(F)F)sc(CCO[Po])c1C</smiles><smiles>[R][n+]1c(C(=O)C(F)(P)PO)sc(CCOP)c1C</smiles>

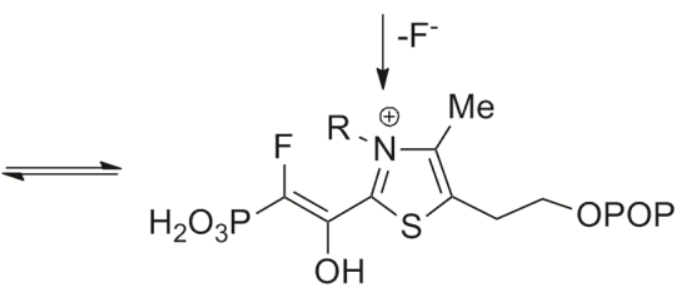

Scheme 2. Proposed mechanism of inactivation of DFPP 
<smiles>CCOP(=O)(CF)OCC</smiles>

Scheme 3. Synthesis of PnDFP.<smiles>CCOC(=O)C(O)(O)[C+]C(=O)P(=O)(OCC)OCC</smiles>

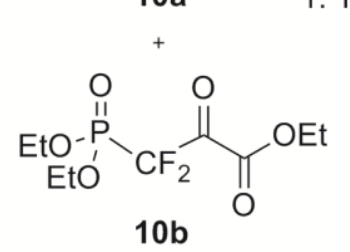

2. $\mathrm{NaOH}$ pH 10

3. Dowex $50 / \mathrm{H}^{+}$

4. $\mathrm{NaOH}$ to $\mathrm{pH} 7$

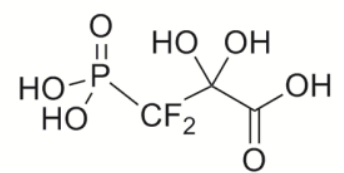

4 as its sodium salt

Scheme 3. Synthesis of PnDFP. 


\section{Graphical abstract}

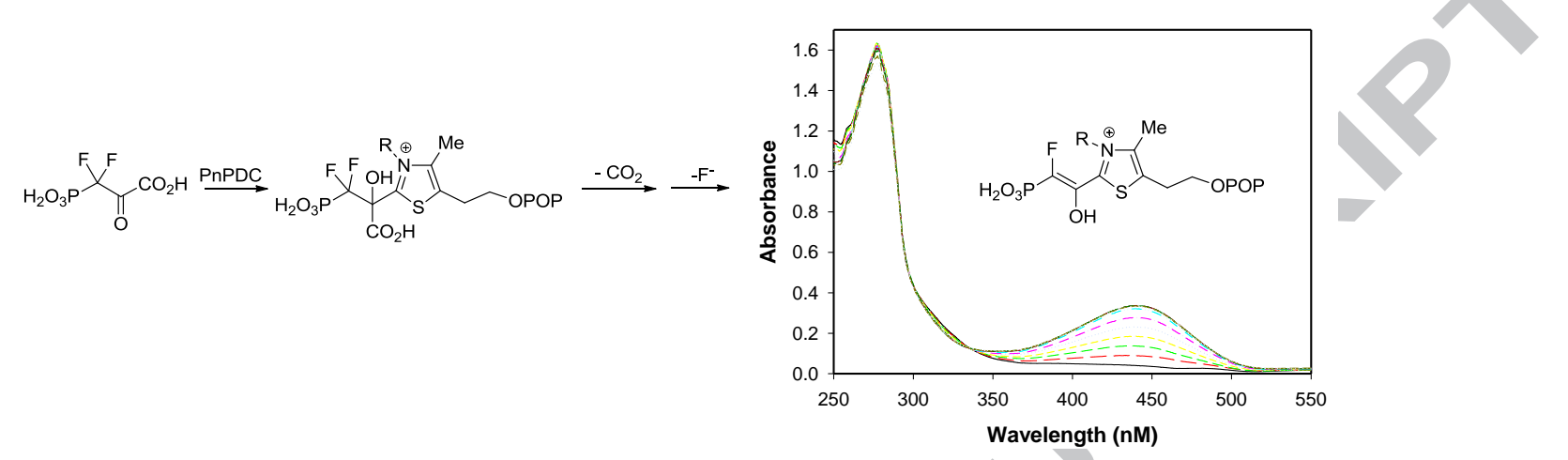

